\title{
Management of huge ascending aortic pseudo aneurysm with transcatheter device
}

\author{
Nadeem Sadiq*, Daud Kamal, Mehboob Sultan, Sohail Aziz, Khurram Akhtar, Syed Asif Akbar shah and Amjad Mehmood and Aziz \\ Pediatric Cardiologist AFIC/NIHD Rawalpindi Pakistan
}

\begin{abstract}
Pseudoaneurysm of ascending aorta is potentially fatal but well-recognized and infrequent complication after cardiac surgeries. The presentation can be varied and may develop early as in our case or may develop even after years. Our patient had VSD closure along with RV band Resection four month earlier to the development of pseudoaneurym. Transcatheter device closure was performed with $24 \mathrm{~mm}$ atrial setal occluder without any procedural complication. To the best of our knowledge this is the largest device ever used for closure of post surgical pseudoaneurysm.
\end{abstract}

\section{Introduction}

Ascending Aortic pseudoaneurysm is a rare and deadly complication after bypass cardiac surgery $[1,2]$. A number of factors play important role in the development of this complication including aortic cannulation site infection, connective tissue disorder, mycotic infections, mediastinitis etc. [3]. The redo surgery require lengthy and meticulous tissue dissection with significantly high mortality and morbidity [4,5]. Transcatheter management of ascending aortic aneurysm is really a challenging, comprehensive and fascinating approach with excellent result and fewer complications [6]. We are presenting a case that underwent VSD patch closure and right ventricle bands resection four month prior to development of this complication.

\section{Case Presentation}

A 24 years old young girl had VSD patch closure and RV bands resection in Feb 2018 with smooth postoperative recovery. She was discharged home at 7 th post-operation days without any complication and remained well during early period. She had mediastinal infection after 2 month of surgery (Apr 2018). The blood counts, blood culture and wound swab cultures were unremarkable. She was managed successfully in outdoor. She again presented with severe chest pain followed by appearance of swelling in lower part of sternum after two months (Jun 2018). She was afebrile, normotensive and having pulsatile swelling at xiphisternum. Blood count, cultures and infection screening was done and cardiac CT was performed immediately. Her blood investigations showed Hb 12gm/dl, TLC 13500/ul, CRP 90mg/dl with normal other labs. The cardiac CT revealed a huge pseudoaneurysm $3.8 \times 3.4 \mathrm{~cm}$ with large defect $(18 \mathrm{~mm})$ arising from aortic cannulation site (Figure 1). She was discussed and planned for device closure considering high surgical mortality and morbidity. She was taken to catheterization suit and aortogram revealed large communication proximal to innominate artery to aneurysm (Figure 2 and Picture 1). The defect measured $19.2 \mathrm{~mm}$ and a superstiff wire parked in the pouch and 14Fr delivery sheath parked in the pouch over the wire. Then $24 \mathrm{~mm}$ ASD device loaded and deployed at appropriate position and repeated injections were given during deployment from innominate artery with right radial approach. There was no pressure gradient across the innominate artery and then the device was unscrewed (Figure 3). The final aortogram showed well placed device with no residual leak (picture 4 and 5). After
72 hours an aortogram was again performed which showed well placed device with no residual leak. The patient was placed on antibiotics and her cultures were negative for any growth so iv antibiotics continued for six weeks. After 6 weeks cardiac was performed that showed well placed device without any distortion of surrounding tissue (Figure 6). She is still asymptomatic and on regular follow up with only on Tab dispirin only (Pictures 2 and 3a)

\section{Discussion}

Psedoaneurysm is fatal and devastating complication after cardiac bypass surgery as in our patient she underwent VSD closure and RV band resection four months prior to development of this complication. The standard surgical management has high morbidity and mortality. Moreover the pseudoaneurysms develop mostly in the postsurgical condition as in our patient, where the adhesions require lengthy and meticulous tissue dissection, a constant issue in surgical management [7]. Transcatheter techniques including thrombin injection in the sac,coil embolizations has been attempted with fewer complications but the device closure of pesudoaneurysm has shown better results [8$10]$. We used $24 \mathrm{~mm}$ device as the neck of psuedoaneurysm was $20 \mathrm{~mm}$. We did not face the threatened procedural complication like rupture of pseudoaneurysm during placement of wire and large bore $14 \mathrm{Fr}$ sheath. As there was evidence of infection in our patient so we continued intravenous antibiotics for six weeks and patient is now healthy and fine (Pictures $3 \mathrm{~b}$ and $3 \mathrm{c}$ ).

\section{Conclusion}

Pseudoaneurysm from the ascending aorta can be safely and effectively managed by transcathter closure using atrial septal occluder with excellent immediate- and short-term outcome.

${ }^{*}$ Correspondence to: Sadiq N, MBBS, MCPS, FCPS (pediatrics), FCPS (pediatric cardiology), Pediatric Cardiologist AFIC/NIHD, Rawalpindi, Pakistan, E-mail: drnadeemsadiq@yahoo.com

Received: September 28, 2018; Accepted: October 22, 2018; Published: October 25,2018 

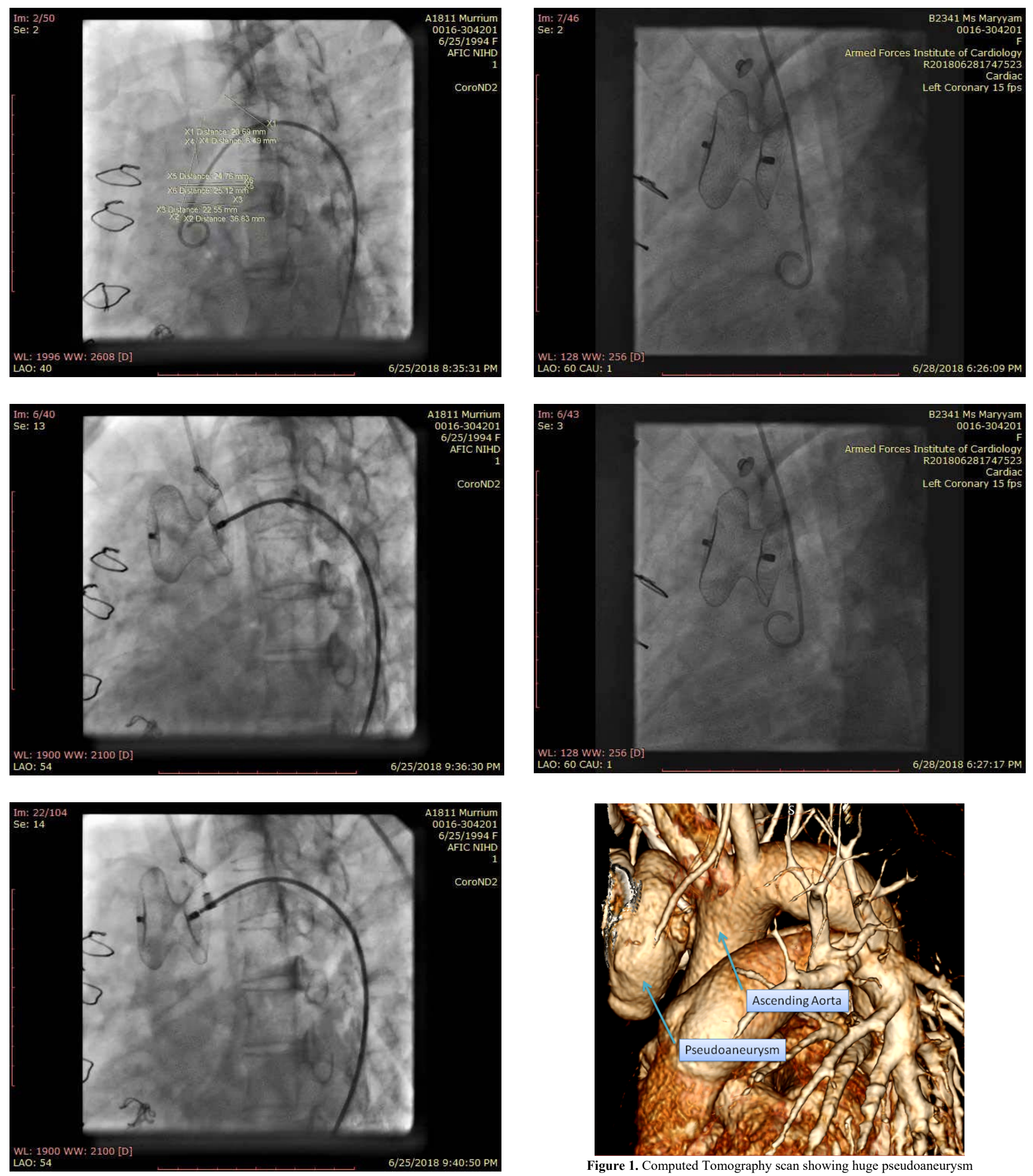


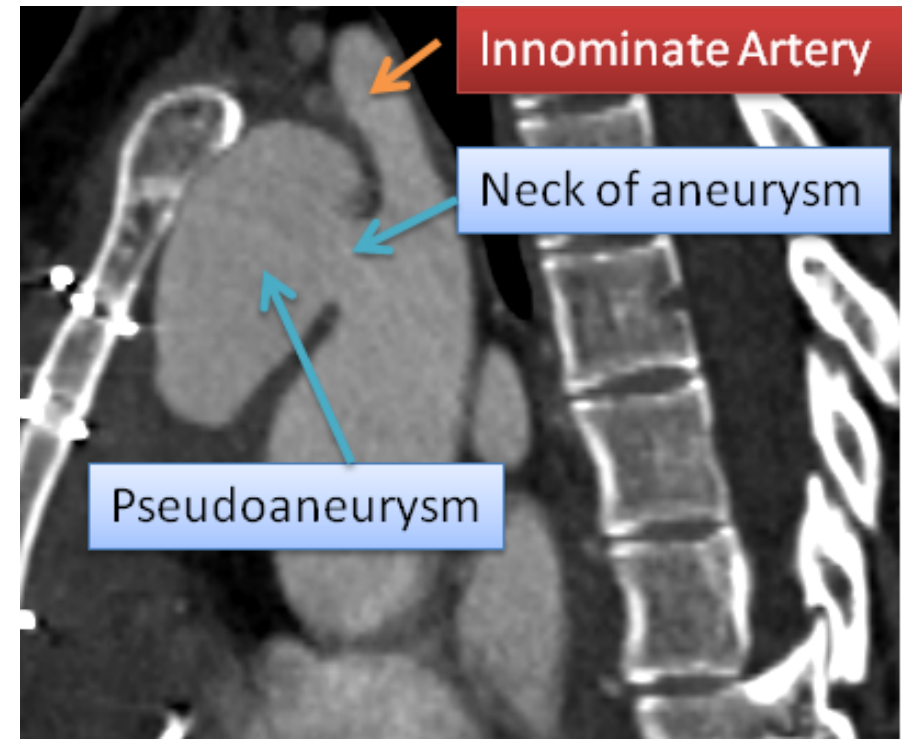

Figure 2. Showing origin of pseudoaneurysm close to Innominate artery

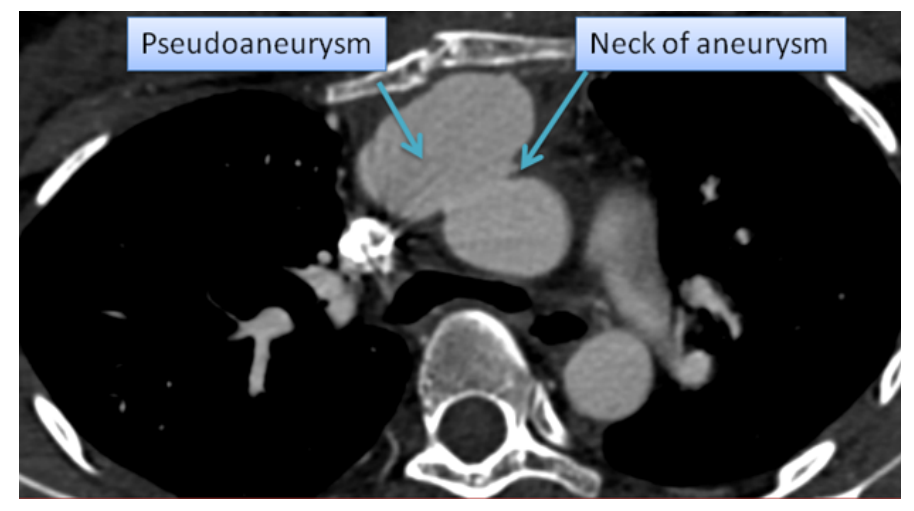

Figure 3. Showing huge neck of pseudoaneurysm measuring $20 \mathrm{~mm}$

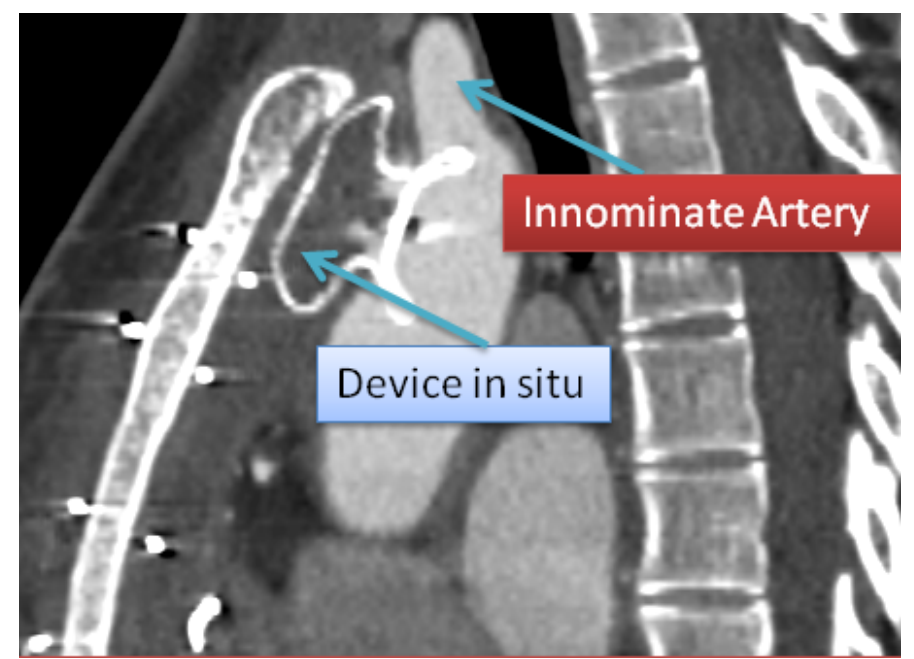

Figure 4. Computed Tomography scan 6 weeks after the procedure showing well placed device 


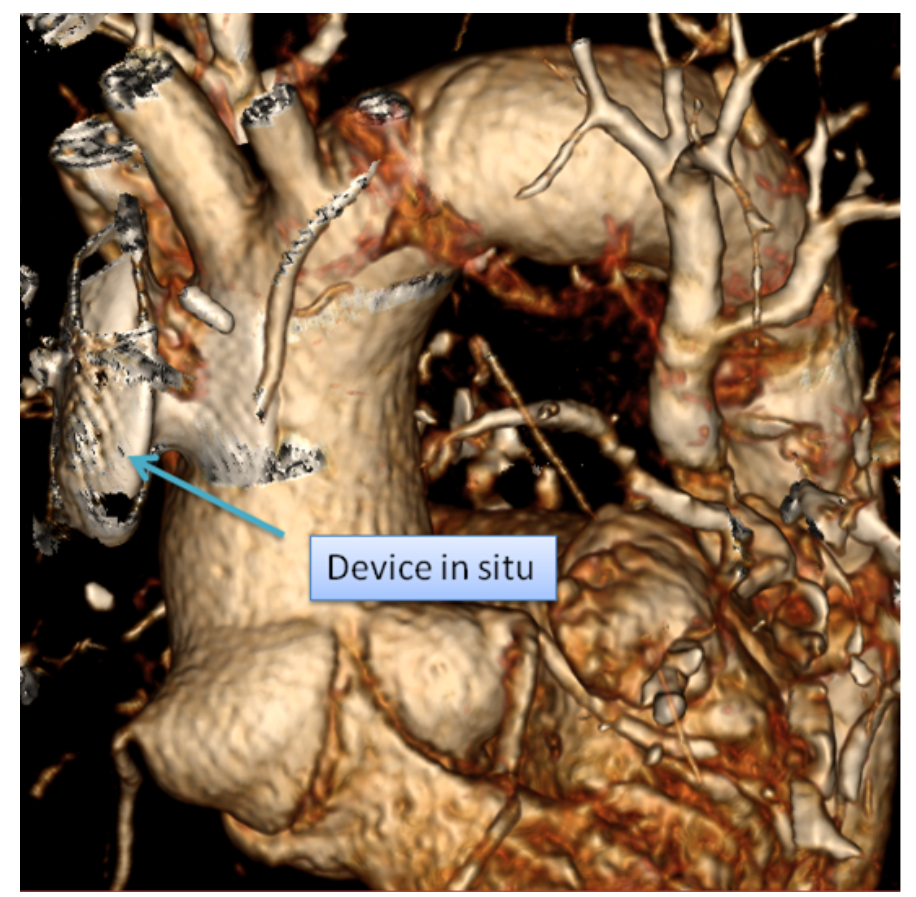

Figure 5. Computed Tomography scan 6 weeks after the procedure showing well placed device
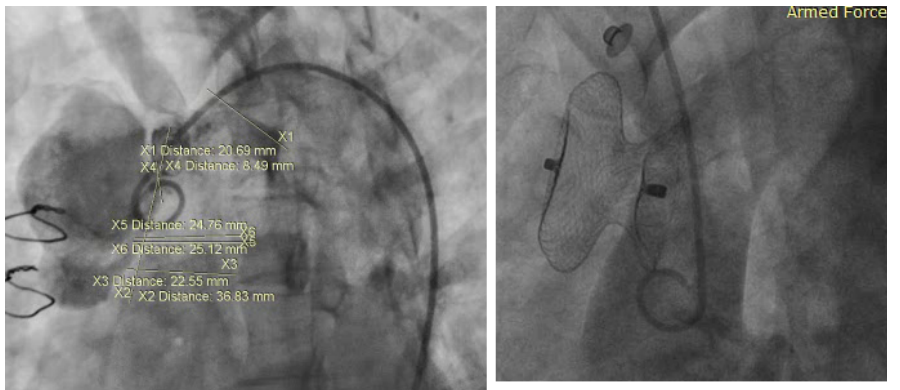

Figure 6. Armed Force

\section{References}

1. Razzouk A, Gundry S, Wang N, Heyner R, Sciolaro C, et al. (1993) Pseudo aneurysms of the aorta after cardiac surgery or chest trauma. Ann Surg 59: 818-823.

2. Mulder EJ, van Bockel JH, Maas J, van den Akker PJ, Hermans J (1998) Morbidity and mortality of reconstructive surgery of noninfected false aneurysms detected long after aortic prosthetic reconstruction. Arch Surg 133: 45-49.

3. Sullivan KL, Steiner RM, Smullens SN, Griska L, Meister SG (1998) Pseudo aneurysm of the ascending aorta following cardiac surgery. Chest 93 : 138-143.

4. Dougenis D, Daily BB, Kouchoukos NT (1997) Reoperation on the aortic root and ascending aorta. Ann Thorac Surg 64: 986-992.

5. Lin PH, Kougias P, Huynh TT, Huh J, Coselli JS (2007) Endovascular repair of ascending aortic pseudoaneurysm: Technical considerations of a common carotid artery approach using the Zenith aortic cuff endograft. J Endovasc Ther 14:794-798.
6. Hussain J, Strumpf R, Wheatley G, Diethrich E (2009) Percutaneous closure of aortic pseudoaneurysm by Amplatzer occluder device-case series of six patients. Catheter Cardiovasc Interv 73: 521-529.

7. Misra S, Koshy T, Patro SN, Dash PK (2009) Large pseudoaneurysm of aortic root after aortic valve replacement for rheumatic heart disease: A rare complication. Ann Card Anaesth 12: 152-153

8. Lin PH, Bush RL, Tong FC, Chaikof E, Martin LG, et al. (2001) Intra-arterial thrombin injection of ascending aortic pseudoaneurysm complicated by transient uschemic attack and rescue with systemic abciximab. J Vasc Surg 34: 939-942.

9. Chapot R, Aymard A, Saint-Maurice JP, Bel A, Merland JJ, et al. (2002) coil embolization of an aortic arch false aneurysm. $J$ Endovasc Ther 9: 922-925.

10. Kanani RS, Neilan TG, Palacios IF, Garasic JM (2007) Novel use of the Amplatzer septal occluder device in the percutaneous closure of ascending aortic pseudoaneurysms: A case series. Catheter Cardiovasc Interv 69: 146-153.

Copyright: $\odot 2018$ Sadiq N. This is an open-access article distributed under the terms of the Creative Commons Attribution License, which permits unrestricted use, distribution, and reproduction in any medium, provided the original author and source are credited. 